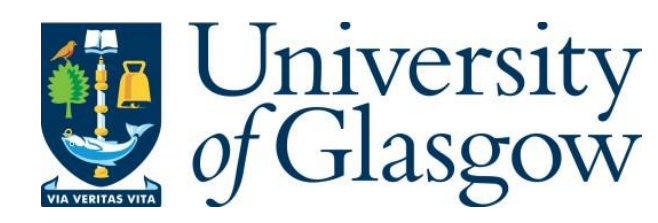

Heddon, D. and Porter, S. (2017) Adapting to the future: vulnerable bodies, resilient practices. In: Ersoy, A. (ed.) The Impact of Co-Production: From Community Engagement to Social Justice. Series: Connected Communities. Policy Press: Bristol, pp. 179-200. ISBN 9781447330295

There may be differences between this version and the published version. You are advised to consult the publisher's version if you wish to cite from it.

\title{
http://eprints.gla.ac.uk/142945/
}

Deposited on: 29 June 2017

Enlighten - Research publications by members of the University of Glasgow http://eprints.gla.ac.uk 


\section{Adapting to the future: vulnerable bodies, resilient practices}

Deirdre Heddon \& Sue Porter

Tony: Right, I think this is recording.

Terry: $\quad$ Here we are/

Glenise: $\quad$ At the start of our walk in Badocks wood.

Paul: $\quad$ So here we are at - what's this place called?

John: $\quad$ No 1 the Harbour Side.

Sharon: Ok, so today's walk is going to be around the Bristol docks.

(Heddon, 2015, 179) ${ }^{1}$

\section{INTRODUCTION}

In this chapter, we are concerned with the contribution of arts-based approaches to support participation in service of a fairer society. As illustration, we offer an account of the Walking Interconnections: Researching the Lived Experience of Disabled People for a Sustainable Society project and the interventions that the project and its outcomes have staged not only in environmental discourse and debate about inclusive public space, but also in representations of walking practices. We start by describing and contextualising the Walking Interconnections project, before going on to consider the arts based approaches used within the project and the research findings they enabled.

Walking Interconnections brought disabled people and sustainability practitioners together to share walking encounters in public places. Through mapping, talking, walking and reflecting together they entered each other's life-world's. Their experiences are caught in photographs, maps and Going for a Walk, a verbatim play crafted by Deirdre Heddon from the recorded conversations of the walkers.

Throughout the chapter, we include co-researchers' voices using excerpts from Going for a Walk.

\section{THE WALKING INTERCONNECTIONS PROJECT}

Walking Interconnections was a two year-long interdisciplinary research project funded by the UK's Arts and Humanities Research Council (AHRC), as part of their

\footnotetext{
${ }^{1}$ Going for a Walk is a 30 minute verbatim audio-play, intended to be listened to whilst walking. The content of the play is taken entirely from words spoken by Walking Interconnections co-researchers, extracted and arranged by Heddon. The play can be listened to/downloaded at http://walkinginterconnections.com/audio-play-going-for-a-walk/ It is also published in Studies in Theatre and Performance (2015).
} 
research theme, Connected Communities. ${ }^{2}$ It responded to the demonstrable lack of connection between disability and environmental movements (Imrie \& Thomas, 2008; Abbott \& Porter, 2013). ${ }^{3}$ More pointedly, it was motivated by the marginalisation of disabled people within and by environmentalist discourse. Such discourse most often presumes, figures and thus reiterates a normative, undifferentiated and able-bodied subject. Sarah Jaquette Ray's insightful identification of a 'corporeal unconscious' within USA environmental thought (2009, 261) has resonance in our location of writing, Britain. Walking Interconnections set out to explore disabled people's everyday practices of resilience.

As suggested by the project's title, a key method of research used in Walking Interconnections was walking. Whilst the project's intention was not, at the outset, to challenge discourses of walking per se - though walking is often part of environmentalist agendas - Heddon's ongoing interest in walking as a mode of aesthetic practice $(2012,2014)$ led to an additional focus on the ways in which representations of walking in critical literature are similarly exclusive.

Finally, whilst recognising that the visibility of disabled people as knowledgeable and resilient subjects is important politically and practically, we acknowledge also that resilience, as a mode of practice and aspiration, carries its own politics. We offer vulnerability as productive resistance to neoliberal subjectivities.

As part of the AHRC Connected Communities programme, Walking Interconnections developed as a collaboration between academics and a community led organisation, The West of England Centre for Inclusive Living (WECIL). Four academic investigators led the project: Dr. Sue Porter (University of Bristol), Professor Deirdre Heddon (University of Glasgow), Dr. Shawn Sobers (University of West of England) and Dr. Suze Adams (University of West of England). The academic researchers were drawn from across the fields of social science, arts and humanities. The research team also involved two non-academic partners: environmentalist practitioner Alison Parfitt, and peer support co-ordinator for WECIL, Anna Wheeler. The project worked with 19 co-researchers (with the support of personal assistants). Whilst Heddon and Porter are the authors of this article, much of the research upon which it draws was created by all those involved in the project: Tony Benson, Liz Crow, Dale Durrant, Hayley Hellings, Tom Henfrey, Anais Leger, Sue Liebow, Sharon Millard, Glenise Morgan, Karen Morgan, Neil, Paul Noone, Courtney Planter, Raheela Raza-Syed, Soledad Riesta, Terry Searle, Rosalind J Turner and Julie Whittaker.

\footnotetext{
${ }^{2}$ For further information on Connected Communities see http://www.ahrc.ac.uk/FundingOpportunities/Research-funding/Connected-Communities/Pages/ConnectedCommunities.aspx

${ }^{3}$ Discourses of environmental health do forge a relationship between environmentalism and disability: toxic environments are held responsible for debilitating illness with evidence of such illnesses an environmental call to arms. Alison Kafer, while acknowledging 'the exploitation of bodies and environments', at the same time notes the ableist and normalizing assumptions often circulating in this relationship: 'illness and disability appear almost exclusively as tragic mistakes caused by unnatural incursions into or disruptions of the natural body and the natural environment' $(2013,157-8)$.
} 


\section{$\underline{\text { Context }}$}

Liz: $\quad$ Ok, so we've come past the nature reserve and got onto a track that we were both getting really quite enthusiastic about, it's one of those very sustainable tracks, tramped down earth and my trike has coped just about with the loose gravel surface on it. And beyond this gate we've come to what looks lovely, real potential for open countryside but we've come to one of those kissing gates which is impassable. I would probably get stuck in and left there because I think I would get wedged. And there's a lovely big gate next to it - but unfortunately that's padlocked - so that's the end of this route. So - now we are going to backtrack.

(Heddon, 2015, 183)

Led by a team of four researchers drawn from across the arts and social sciences, the key aim of Walking Interconnections was to identify disabled people's wisdoms (Leipoldt, 2006) as these relate to debates about and planning towards environmentally and socially sustainable societies. By sustainable we mean the ability to sustain life on earth. ${ }^{4}$ Key aspects of the transformation towards sustainability are the abilities to cope with and adapt to new challenges arising from changing environments (John \& Kagan, 2014, 61). The project developed strategically from earlier scoping work undertaken by David Abbott and Sue Porter, extending the literature review and small focus-group surveys documented in their essay, 'Environmental Hazard \& Disabled People: From Vulnerable to Expert to Interconnected' (2013). In that essay, the authors ask whether disabled people's experiences might enable them to become valuable contributors to planning initiatives directed towards sustainability, rather than marginalised by the dominant perception of disabled people as singularly vulnerable.

One catalyst for this scoping study was the perceived vulnerability of disabled people in the event of environmental hazard, acknowledging too that extreme weather events, as a result of climate change, are rising (Fischer \& Knutti, 2015). Abbott and Porter acknowledge that disabled people are vulnerable - that is, disproportionately affected in crises situations. However, their contention is that such vulnerability is a product of both neglect (for example, structural attitudes position disabled people as the least worth saving) and design (for example, the needs and skills of disabled people are not fully acknowledged because planning responses are often ablest in their assumptions, privileging normative notions of bodily abilities). Problematising the perception of vulnerability, Abbott and Porter propose an alternative hypothesis, one which pays attention to disabled people's 'intricate, daily negotiations with risk, hazard and barriers' $(2013,840)$. As they argue, 'disabled people may have lived experiences which bestow expertise which could significantly contribute to discussions about and planning for environmental risk' (ibid.). Tactically appropriating and redeploying environmentalist rhetoric, Abbott and Porter remind the reader that it is wasteful to marginalise those knowledge-resources which might well offer innovative ways to view and understand our relationships with each other, including more-than-human others.

\footnotetext{
${ }^{4}$ We have already failed, of course, since many species have not been sustained; environmental crisis is not a feature of the future but of the present. See Morton (2010).
} 
Focusing attention on the contributions that disabled people can make to sustainability discussions and planning, Abbott and Porter's essay seeks also to move beyond the more established debates around issues of access. Whilst there is no denying the continued existence of environmental injustice enacted through uneven geographies which serve to exclude, or at the very least challenge, certain bodies in certain spaces (Imrie \& Thomas, 478), Abbott and Porter are interested in what those bodies and minds do in those spaces, whether easily accessible or not; and, significantly, what that doing can teach us.

In the concluding paragraph of their essay, Abbott and Porter confirm their impression that disabled people's 'wisdom', gained through everyday experience, may well relate to: 'overcoming barriers; responding to risk; understanding the importance of the relational; and, appreciating the limits rather than the limitlessness of things' $(2013,851)$. They also admit to a desire to explore this hypothesis in the future and, more specifically, to develop methods which would enhance dialogue between disabled people and environmental activists. Walking Interconnections is positioned here as the sequel to that scoping study, moving beyond the review stage and from the theoretical and hypothetical to the everyday and practical. Members of the WECIL Peer support group were participants in a focus group in the scoping study and their input shaped both that essay and the Walking Interconnections project.

From marginal to valuable

Tony: $\quad$ There's this bridge, that's a footbridge, so these are all footpaths, these purple coloured things on the map, so we could maybe investigate that?

Sue: $\quad$ As long as we've got some options in case it doesn't work.

(Heddon, 2015, 179)

Our commitment to identifying and communicating the values of disabled people's everyday knowledges corresponds with the recent work of Rosemarie GarlandThomson, particularly her essay, 'The Case for Conserving Disability' (2012). Two points made by Garland-Thomson are especially pertinent to Walking

Interconnections: 1) 'disability is inherent in the human condition' and, 2) disability is 'a potentially generative resource rather than [an] unequivocally restrictive liability' (2012, 339). Recognising disability as inherent to all people - 'the transformation of flesh as it encounters world' and 'the body's response over time to its environment' (342) - Garland-Thomson proposes radically that 'what we call disability is perhaps the essential characteristic of being human' (342). Given this, disability is neither 'unusual [n]or avoidable' but instead is firmly a part of each of our lives (342).

Garland-Thomson's discussion of disability as an evolving practice of a body located in time complements the work of her essay 'Misfits: A Feminist Materialist Disability Concept' (2011), where the body is located in space too. Garland-Thomson proposes disability as

a shifting spatial and perpetually temporal relationship [which] confers agency and value on disabled subjects at risk of social devaluation by highlighting 
adaptability, resourcefulness, and subjugated knowledge as potential effects of misfitting (592, italics added).

In her extension of social constructionist theory towards dynamic materiality, Garland-Thomson shares much with the non-representational approach some cultural geographers take to exploring co-constitutive body-landscape relations, moving from disembodied thought to embodied thinking, action and relations. As Anderson and Harrison summarise, 'Insisting on the non-representational basis of thought is to insist that the root of action is to be conceived less in terms of willpower or cognitive deliberation and more via embodied and environmental affordances, dispositions and habits' $(2010,7)$. From this frame of reference, nothing is fixed or given, since everything is in relation and in a perpetual state of becoming, 'dynamic phenomena produced through entangled and shifting forms of agency inherent in all materiality' (Garland-Thomson, 2011, 592). From here, one does not perceive a disabled person excluded from a fixed and settled world but approaches, instead, the process of world-making.

For Garland-Thomson, 'misfit' is a 'critical keyword' that denotes an encounter in which the relationship between two things is one of disjunction and incongruency (592). The benefit of this approach is that the 'problem' is inherent to neither of the two things, but rather their juxtaposition. With a shift in spatial and temporal context, there might well be a fit rather than a misfit. As she writes, 'Misfit emphasizes context over essence, relation over isolation, mediation over origination' (593). 'Misfitting' is offered as a way to theorise disability as a becoming that emerges from material arrangements that materialize disabled subjectivity at the same time as they materialise misfitting spaces (for example, the relation between a wheelchair user and a stair) (594). Misfitting opens up a space to (re)claim agency and to negotiate different relationships.

Disability's value - a value that prompts Garland-Thomson to argue for conserving disability - begins to emerge here also: 'fitting' tends to erase consciousness of the always-contingent in-between, the dynamism of our relations. This dynamism is brought home through the performance of misfitting because it affords an opportunity to become sensitized to material experience, igniting 'a vivid recognition of our fleshiness and the contingencies of human embodiment' (598). Misfitting reveals that the world is far from 'stable, predictable, and manageable' (598). Garland-Thomson closes 'Misfits' by listing six reasons why disability - misfits - should not be extirpated but should rather be valued as a 'form of human variation'. The sixth of these has the most bearing on Walking Interconnections and is worth quoting at length:

The moral understandings, subjugated knowledge, or ethical fitting that can emerge from what might be called socially conscious, or even theoretically mediated, misfitting can yield innovative perspectives and skills in adapting to changing and challenging environments. Acquiring or being born with the traits we call disabilities fosters an adaptability and resourcefulness that often is underdeveloped in those whose bodies fit smoothly into the prevailing, sustaining environment. This epistemic status fosters a resourcefulness that can extend to the nondisabled and not yet disabled as they relate to and live with people with disabilities (604). 


\title{
Walking Interconnections
}

\begin{abstract}
Anais: $\quad$ Why did I volunteer? Because I was interested in the aspect of action research - something different, going outside, experiencing, reporting about what you felt outside and how you experience your environment.

Liz: $\quad$ As a long-term wheelchair user and a trike user l'm looking always for new routes but there's a risk in trying out a new route that you don't know it's passible until you've tried it and if you don't know it's passable can you try it? So for me there's the potential of having a hike and trike buddy to try out a couple of new routes with, to try and extend the repertoire and see what the experience of doing the route is with somebody else.
\end{abstract}

Tom: $\quad$ When you are new to a place you learn a lot from walking around with people who know it. I felt it would be very interesting to learn about the place itself from the perspective of somebody who is experiencing it in quite a different way from me.

(Heddon, 2015, 178)

Walking Interconnections adopted a participatory research approach, with arts-based methods utilised as both research tools and outputs. Recognising the typical disconnection between two communities, disabled people and sustainability practitioners (see Imrie \& Thomas, 2008; Abbott \& Porter, 2013), we saw value in the exchange of experiences between them. This is not to suggest that there are not people who identify as both disabled and as environmental activists. However, research to date does suggest that there is little collaboration between these two communities. We recognise also that 'community' is a complex term, and one that risks homogenising differences and erecting boundaries. Whilst many of our disabled co-researchers were drawn from a peer support group facilitated by WECIL, and in that sense might be regarded as a definable 'community', other co-researchers selfidentified a performed identity, without necessarily being part of a constituted community. Our commitment to participative enquiry and our project's location within the AHRC's Connected Communities thematic prompted us to position our 'subjects' as co-researchers. ${ }^{5}$ Over the course of a year we worked with 19 co-researchers from the Bristol area, who self-identified as either disabled or as environmental activist (only one identified as both). We asked each co-researcher to invite another co-researcher to accompany them on a walk of their choice, exchanging experiences of the environment by walking together.

Each participant sketched a map of their proposed journey before and after the walk and they were all invited to select and use creative prompts from a 'Walking Guide' devised by academic co-researcher and artist, Dr. Suze Adams. The Walking Guide functioned as a list of activities, instructions, foci of attention and suggestions for

\footnotetext{
5 The AHRC's Connected Communities funding call was explicit that research projects were conducted with communities, with an intention also to mobilise inter-connections between communities. http://www.ahrc.ac.uk/Funding-Opportunities/Research-funding/ConnectedCommunities/Pages/Introduction-and-vision.aspx <accessed 28 May 2014>
} 
photo and film interpretation of the walk or, more prosaically, 'a collection of moves' to be performed. ${ }^{6}$ The prompts in the Walking Guide, indebted to the popular MisGuides published by Devon-based artists' collective Wrights \& Sites, ${ }^{7}$ were intended to provide frames through which co-researchers could pay attention to the environment (for example, taking photographs of three orange things encountered whilst walking) and at the same time to gather data from each walk (for example, photographic documentation of surfaces encountered). In total, the project has an archive of some 900 photographs. Each walking pair or trio carried a camera and a digital voice recorder. After the walks co-researchers analysed together the walks they had undertaken, surfacing insights through sharing knowledge. Walkers reviewed and annotated the maps they had drawn before and after each walk and selected 'significant' moments depicted in the photographs taken, discussing their choices and what the images represented or meant to them with the full research team. The audio material of conversations - more than 25 hours recorded on the move - was transcribed by Heddon and used to create a 30-minute verbatim audioplay, Going for a Walk. The play was shared in draft form with the co-researchers and once consent was given for the script to be made public, co-researchers were invited to participate in a workshop with Heddon before the play was audio recorded, with co-researchers invited to read their own part. ${ }^{8}$ The play and an exhibition of selected images and walkers' maps were used to communicate the project to a range of stakeholders, including the Environment Agency, Bristol City Council Civil Protection, Public Health and Sustainability units, Neighbourhood Partnerships, Walking for Health, and the Schumacher Institute, and later at workshops, ${ }^{9}$ festivals and conferences including The Glass-House Debate. ${ }^{10}$

\section{Walking as a Participatory Research Method}

Tom: $\quad$ Taking it at a different pace and being more observant and sharing things. I noticed a lot of things that I hadn't spotted before down here, details of even obvious things.

Anais: $\quad$ If I was on my own I wouldn't have experienced the walk in this way at all.

[...]

Anais: I feel it becomes really practical, there is a strong practical side to it, whereas when I walk with my partner, we just discuss abstract stuff, we don't really realise where we walk, how we interact with the ground, this kind of stuff.

\footnotetext{
${ }^{6}$ See http://walkinginterconnections.com/wp-content/uploads/2013/02/Sharing-aWalk_toolkit_v2.pdf

${ }^{7}$ See http://www.mis-guide.com/mg.html

${ }^{8}$ Actors were also employed to stand in for co-researchers who did not want to read their part.

${ }^{9}$ Subsequently the project has contributed to Emergency/Civil Protection planning, the Rockefeller 100 Resilient Cities launch and agenda setting and European Green Capital action groups.

${ }^{10} \mathrm{http}: / /$ www.theglasshouse.org.uk/debate-series-2014-15/
} 
Dale: $\quad$ I hadn't realised how many different types of walking surface there were. It seems as if there was only two but actually there's four or five. There's cobbles, there's tarmac, there's roads, and a sort of paved area as well.

Tom: $\quad$ l've become much more aware of the different people passing through this area. How it works. The diversity of things bringing people in. I've always seen it more as a route for passing through.

(Heddon, 2015, 187)

Our choice of walking as a key research method in Walking Interconnections developed in part out of Heddon's previous interest in the capacity of walking to foster collaboration and facilitation of non-threatening dialogic exchange (2010, 2012). Walking as a research methodology also follows in the footsteps of Anderson's 'walking and talking' interviews (2004), Carpiano's 'go along' interviews (2009), Ingold and Vergunst's peripatetic ethnography (2008) and Heddon and Turner's 'interviews on the move' (2010; 2012). In contrast to researchers such as Anderson, Carpiano and Heddon and Turner, who have used walking as an envelope through which to conduct interviews between researcher and research subject, in Walking Interconnections our 'subjects' were positioned as coresearchers, and their conversation, image making and mapping created the data.

Edensor notes that walking offers a perspective from which life can be both grasped and understood, but also through which identity can be transmitted (Edensor, 2000, 81). Walking can be both performative and communicative, focusing attention on the kinaesthetic, mobile and sensory/felt dimensions of lived experience (Pink et al, 2010). In addition to walking being conducive to collaboration and dialogue, in the context of exploring people's everyday practices walking is an embodied performance which allows reflection on people's affective relationships to and with place (see for example Ingold and Vergunst, 2008; Patterson 2009). Geographers Andrews, Hall, Evans and Colls recently issued an appeal to researchers to pay different attention to forms of embodiment and urban mobility (2012). As they note, and as our own research design aimed to acknowledge, for many people - and for an increasing percentage of the population - walking is undertaken 'through the use of wheelchairs, sticks, scooters, and walking frames', or through slow walking (2012, 1928). Andrews et al., surmising that most work on walkability in the social sciences is focused on issues of access, argue that 'new research needs to be developed paying particular attention to different forms of embodiment, mobility, movement activities, and the places, experiences, agency and cultures involved' $(2012,1930)$.

Walking offers itself as a research method particularly useful to the generation of qualitative data which gestures towards the affective and emotional, as much as towards more tangible issues of access. Through Walking Interconnections, we were interested in our co-researchers' navigation of place alongside the affective dimensions and shifting dynamics of people-people and people-place relations. Walking Interconnections' co-researchers, prompted by the Walking Guide and the dialogic structure of the walk, were walking and thinking bodily about their interaction with the environment, nature, space, community and belonging. Walking locates bodies in space, but at the same time is mobile, offering at the outset a certain propensity towards an attitude of always-in-relation. In the act of walking, as one 
moves through space and is in relation to space, one is always engaged in an unsettled process of becoming, just as place too is always in the process of becoming in relation to the ones who moves through it. Following Rosemarie Garland-Thomson, we are interested in the relationship of flesh to world, with walking offering a key way to explore those relationships. Walking, as our research reveals, has its own particular, contextual practices - that is, ways of walkingworlding.

\section{Interventions into Walking Discourse}

While Andrews, Hall, Evans and Colls' appeal to move away from an ingrained focus on access towards an exploration of embodied practices was issued to health geographers specifically, their request to attend to 'different forms of embodiment' could well be directed to researchers in the arts and humanities too. Walking as an embodied practice has been much explored recently from within different disciplinary perspectives, including anthropology, architecture, design, art and performance. ${ }^{11}$ This critical interest in walking has been matched by a popular one, with articles in newspapers extolling the virtues of walking, exhibitions and art festivals dedicated to programming and reviewing the use of walking in art, and an ever increasing number of walking festivals launched across the UK. ${ }^{12}$ What is striking is that, in spite of the variety of locations in which 'walking' is engaged and discussed, the form it takes as a practice seems decidedly homogenous.

In previous research, Heddon and Turner have critiqued the exclusive and excluding nature of writing about walking, specifically aesthetic walking. As they note in 'Walking women: shifting the tales and scales of mobility' (2012), the constant but unacknowledged reiteration of a particular genealogy, which references mainly male writers and artists, produces something of a canon and orthodoxy of walking practice and theory. The persistent positioning of walking as 'individualist, heroic, epic and transgressive' serves to marginalize other types of practices and the critical insights that these prompt' (224). Whether the location is urban or rural, the scene set is most often a 'wilderness' to be conquered and tamed. Heddon and Turner's aim was not to deny such features as the heroic or adventurous in aesthetic practices, but rather to revise the tropes through mobilising scales - spatial and temporal. What is deemed adventurous, or daring, or innovative is very much dependent on context; creating relations rather than escaping them, making work in familiar locales, or

${ }^{11}$ In April 2015, the AHRC-funded project 'Footworks', a research group attached to the Walking Artists Network, held a workshop and symposium with the University of Falmouth to explore the future of art and walking, entitled 'Where to?' (see

https://footworkwalk.wordpress.com/) More than 70 abstracts were submitted for consideration.

${ }^{12}$ See recent articles extolling the benefits of walking in The New Yorker http://www.newyorker.com/tech/elements/walking-helps-us-think and The New York Times http://well.blogs.nytimes.com/2015/01/21/stressed-at-work-try-a-lunchtime-walk/? $\quad \mathrm{r}=0$ The organisation Walking Festivals UK and Ireland lists 165 walking festivals on its website http://www.walkingfestivalsuk.com/. Walk On: 40 Years of Art Walking launched in London in 2013 and has subsequently toured to Sunderland, Birmingham, Southport and Plymouth (see http://walk.uk.net/portfolio/walk-on). Deveron Arts in Aberdeenshire launched its Walking Institute in the same year (see http://www.deveron-arts.com/the-walking-institute/) 
simply working outside might be usefully reframed as courageous and innovative acts. In any case, Heddon and Turner sought to press the point that a key political potential of walking might very well lie in its practice of relation- and social-making (236).

Though Heddon's previous research therefore calls for and demonstrates attention to gender differences, noting that the seemingly unmarked body figures in much walking criticism is decidedly male, what remains vastly understated and under explored is that this body is also able-bodied/non-disabled. Heddon's work in the field of walking aesthetics is part of the spatial turn in criticism evidenced across the humanities and social sciences since the 1990s, which serves to explain in part the emergence of walking as a legitimate academic focus. However, the subject of walking is curiously normative. Writing from within the discipline of urban design, for example, Filipa Matos Wunderlich references pace and routine in his paper presented at the Walk21-VI conference (2005):

Walking as both an experienced and observed activity in urban space involves regularity and routine. It is performed rhythmically step after step, after step, after step, after step. (Wunderlich, 2005, n.p).

Architectural theorist Jane Rendell writes in a similar vein:

There is a kind of thinking that corresponds to walking, one that follows an itinerary, keeps up a certain pace and remains in constant motion, moving from one thing to another, engaging only in passing (Rendell, 2006, 185).

Ingold and Vergunst propose that walking is 'an accomplishment of the whole body in motion' and demand that we 'pay attention to experiences of tactile, feet-first, engagement with the world' $(2008,2)$. In summary, even where walking is the specific focus of analysis, much remains taken for granted and presumed to be in common, including rhythms, paces, speeds, movements, atmospheres; indeed, bodies and the very act of walking itself.

These presumptions about walking prompt fundamental questions: what is walking and who is walking? Such homogeneity also, though, fosters certain answers. As one of our co-researchers, Liz Crow - a wheelchair user - commented on the Walking Interconnections blog in June 2013, she bit her 'tongue at the word walking (because I'm not, am I?)' (Crow, 2013a). Notably, six months further into the Walking Interconnections project, Crow's use of the word walking, admittedly still somewhat hesitant, does indicate an importantly expanded signification:

Speaking personally, so many years of medical history have been of doctors telling me I should walk - that is, functionally, place one foot in front of the other in order to move from one point to another. In almost 30 years of using a wheelchair, I've never yet seen a doctor who understood that that's not what walking ever represented to me. It was moving through space, connecting with natural and social environments, relationships, meditation, relaxation, pleasure, mental health, tactility, and more. Those are the really important features of walking and it remains all of those things when I 'walk' with wheels (Crow, 2013b). 
Crow goes on to explain to the reader of this blog why she chose a recreational walk to undertake as part of the Walking Interconnections project. What Crow makes clear is that, ordinarily, any type of walking she does requires careful planning, what she refers to as 'the dry stuff'. Participating in Walking Interconnections, and walking with a non-disabled partner, allowed her a moment of reprieve from that auxiliary and 'joyless' activity, and to experience the pleasure of walking. As she writes, 'The point for me of Walking Interconnections was to explore liberation from that; it was about reconnecting with all those other things that walking always represented to me and that the medics never knew'. Going on a walk, in some contexts, is to generate greater dependency on people rather than less, precisely to mitigate risk and realise pleasure.

Walking Interconnections allows for a disruption of the taken for granted and the unstated. Discussing with our co-researchers their experiences, and listening to their audio-recordings, it is clear that, at least for some of the time, for some people indeed, for increasing numbers of people - there is no rhythm to walking that it is easy to fall into, because the sometimes precarious inter-relationship of body and environment prevents flow; walking is varied in its tempo, with obstacles looked out for, detected and navigated, or not; pace is disjointed and fragmented because necessarily punctuated with essential periods of stillness allowing the body to rest and recover; when one's attention is always scanning for the challenges ahead, preparing to negotiate them, and then skilfully doing so - or not - there is little time to allow the mind to drift off into diversions. As Crow notes in her earlier blog entry, 'what should be pleasure is predominantly anxiety. Pleasure is mainly a thing of hindsight rather than in the moment. [...E]ven at its best there is always an undercurrent of fear' (Crow, 2013a).

For many people, and for increasing numbers of people, going for a walk does not bring feet into contact with ground. The connection is wheels to ground. Is the wheelchair user's experience of walking - with the haptic running from ground to wheels through arms and to the rest of the body - any less 'environmental' than the walker whose shoe-soles touch pavement? The phenomenological analytic underpinning much of the writing about walking, motivated by an exploration of the relationships between bodies immersed in places, shares the corporeal unconscious noted by Ray (2009). This tends to conjure unproblematised relations between a singular walking body and a connection and intimacy with the world, which is surely one aspect of a predominant environmental ethic. For Ingold, steps and breath are connected to air and ground (2010). But for the walker in a wheelchair, the body itself is simultaneously mobile and static and one cannot presume, for example, that the body moving through space in a wheelchair is made warm; atmosphere and weather are experienced - known, felt - differently.

The constant reiterations of embodiment lying in particular foot-to-ground phenomenological experience perhaps explains Crow's stated frustration during a walk for the AHRC's Connected Communities Festival held on Cardiff Bay (2014). As we explored the environment, mapping out an accessible route for participants, Crow perceived that a steep bank next to the path prevented her from really getting close to nature, over there - as if nature, or the environment even, was out of bounds to her. We would argue that it was not the bank that excluded Crow from getting close to nature but ideas of nature; where it lies, and how (particular but unmarked) bodies 
connect to or access it. ${ }^{13}$ Challenging nature's location and every body's connection to it - every body's immersion it - is surely part of a sustainability ethic, one that might well also challenge the perceptible disconnection between the disability and environmental movements.

\section{Embodied Wisdoms}

Sue: $\quad$ I think we are going to get knocked over in a minute. [Referring to the bikes].

Tony: $\quad$ I think this is probably the first time l've walked along this path. Whereas before I've always been one of the people on a push bike.

Julie: $\quad$ That's obviously another walk.

Anais: $\quad$ You couldn't go there?

Julie: $\quad$ No. I don't think it would be a good idea with the scooters.

Anais: $\quad$ There is a step there.

Sue: $\quad$ Oh, sorry [getting out of the way of a man on a bike].

Paul: $\quad$ Oh, cobbles.

Raheela: I hate them.

Julie: $\quad$ With a scooter I have to be aware of everything, people around me, children, everything.

Sue: $\quad$ Is it safe for me to come out and get closer? I don't want you to get mowed down.

\section{$[\ldots]$}

Sue: $\quad$ [Referring to bikes] It's very dangerous here, isn't it?

Tony: $\quad$ You have to give way, but I think the problem of this is that when you are on a pushbike you begin to think of this as a motorway for bicycles.

Sue: $\quad$ It feels like a motorway for bicycles.

$X \quad$ [Man on bike]: Excuse me.

Sue: $\quad$ Oh, sorry! [getting out of the way]

(Heddon, 2015, 184)

Walking Interconnections sought to identify the skills and strengths that make up disabled co-researchers' wisdom. Leipoldt (2006) writes of disabled people's experience in making real choices; moving beyond the rhetoric of rights to value individual choice; acknowledging limits, judging what to accept and what is open to change; skilfully 'riding the wave', rather than seeking to control it; bearing up

${ }_{13}^{13}$ In fact, what was 'over there' was a man-made saltmarsh. 
through committed relationships, with oneself, others and the environment; and, creativity in living, and personal transformation.

Our co-researchers' analysis of the walking-together experience identified repeated practices of risk taking, deviation, adaptability, problem solving, persistence and creativity. This mixture of 'practical' skills such as risk assessment and problem solving, and developed 'traits' such as persistence (often referred to by coresearchers as stubbornness) and creativity, map well onto definitions of resilience. For example, the Rockefeller Institute's tabulation of resilience features, 'qualities needed to evolve and emerge stronger' in the 'face of acute shocks and chronic stresses', though attached to an abstract notion of 'a city', shares a correspondence with our findings. ${ }^{14}$ Our disabled research participants demonstrated variously the capacity to be: 'Accepting of uncertainty and change'; 'Reflective'; 'Adaptive'; 'Robust'; 'Resourceful' and 'Diverse (flexible)'. ${ }^{15}$ Based on our research, we would add to this list of resilient qualities 'Persistent', 'Committed', 'Attentive' and 'Interdependent'. Garland-Thomson offers several examples of similar assets, including strategic planning and time management skills, navigational skills used by blind people and people with low-vision, and sign language which can communicate across long distances $(2012,346)$. Appreciation of these skills supports our original challenge to the notion of disabled people as only vulnerable, recognising a set of abilities held in different measure across our group of co-researchers.

While the project has allowed us to understand more about different forms of resilience in support of the transition to a sustainable society, it has also highlighted aspects of social injustice, some of which have otherwise been too easy to overlook, for example illustrating the absence of the disabled body within spaces typically coded as explicitly 'environmental' - e.g. heritage sites and 'natural' landscapes'. Of the 900 photographs taken while walking in public areas, it is startling that only a tiny number of these show any other visibly disabled people. One risk when researching with disabled people is that the more textured aspects of ableism get flattened into a reactive focus on physical access - such as the use of stiles, small kissing gates, and ornamental cobbles in heritage areas - losing the subtleties of insidious exclusion. The body is the fleshy substance of citizenship (Wiseman, 2014). Simply addressing physical barriers with, usually limited, 'special provision', sends out clear social messages about what constitutes a normal body, and who is a full citizen.

Walking Interconnections demonstrated that 'ability' is a dynamic definition for all human subjects, shifting depending on relations with and to space and time (some people feel more energetic in the morning, more vulnerable in the cold, etc.). Meekosha and Shuttleworth write that

[h]ow societies divide 'normal' and 'abnormal' bodies is central to the production and sustenance of what it means to be human in society. It defines access to nations and communities. It determines choice and participation in civic life. It determines what constitutes 'rational' men and women and who should have the right to be part of society and who should not $(2009,65)$.

\footnotetext{
${ }^{14}$ These resilient features could be tied to both engineering and ecological models of resilience, that is, the capacity to bounce-back or to change and adaptation.

${ }^{15}$ Two other qualities noted by the Rockefeller Institute - 'Inclusive' and 'Integrated' - are less easily detached from the model of resilient city and attached to a person.
} 
Logically, the citizen is embodied, and the (private) body performs its citizenship in the public sphere. Lister points out that citizenship has traditionally been associated with the 'public' sphere and the body with the 'private' sphere, resulting in the distancing of the body from citizenship. This demarcation has resulted in the exclusion of particular groups of people from being able to achieve full citizenship based on corporeal difference (Lister 2003). This public/private division mirrors the more simplistic social model interpretations of disability/impairment, where the social environment is blamed entirely. The social model of disability has been criticised for denying the embodied realities of pain, fatigue and other affects of impairment for many disabled people. In Wiseman's study of disabled young people,

The everyday negotiation of feelings of 'sameness' and 'difference' were found to be important in understanding how participants felt about themselves in relation to their everyday citizenship. Families and friends were instrumental in promoting feelings of 'sameness' whilst feelings of 'difference' emerged in relation to inaccessible toilets, [...] clothes shops and through negative interactions with non-disabled others. Citizenship and inclusion were invalidated where participants were made to feel 'out of place' because of corporeal difference (Wiseman, 2014).

Walking Interconnections' co-researchers reported similar feelings of acceptance and 'sameness' with their walking partners, sustained by the walking and talking. The dialogue produced by this 'being in place together' enabled their exploration of 'difference' occasioned by their different embodied experience of the environment they were walking in. In this way the 'personal' experience of individuals with impairments was reunited with the 'public' persona of disabled citizens.

As noted earlier, Walking Interconnections arose from an awareness of a lack of connection between disability and environmental movements and one thing our research revealed was the failure to find common cause. This lack of connection between communities appeared to have led to local planning for shared routes being primarily responsive to vociferous cycling campaigns, rather than being equitably informed by the needs of other groups. In this way, we found the uplift in cycling initiatives has ironically impacted negatively on disabled people's experiences of supposedly shared walking/cycling routes. The design of the space, as one of our non-disabled co-researchers, himself a cyclist pointed out, allowed some cyclists to treat the whole space as if commuting on a motorway, putting pedestrians and wheelchair users at risk.

As well as skills noted above, co-researchers also demonstrated strengths, by which we mean the more relational aspects of resilience, such as acceptance of the necessity and desirability of interdependency. For example, disabled walkers, recognising rather than denying their vulnerability, utilised the relationship with their walking companions to experiment and to be playful; as one walker said, 'as a disabled person you have to break the rules sometimes'. Another participant reflected on the benefit of having someone to walk with; should things get really rough, her companion walker could go for help. Whilst interdependency signals shared vulnerability, it also paradoxically permits greater liberation and in this context, experimentation and risk-taking. 
In reflecting on the notions of interdependence and relationality, we found that the dominant discourse of 'independence', particularly as this is attached to the field of disability policy and practices, but also more generally in current discourses in relation to what constitutes a 'good citizen' and a 'good life', belies the reality and necessity of interdependence - interdependence offering alternative and useful conceptions of 'sustainable living'. Repeatedly observed in our project were interdependencies' attendance practices of trust, negotiation, reciprocity, mutuality, and co-operation.

Resilient Knowledge

Roz: $\quad$ Off to our right is a bird hide which is up several steps. And then in front of us is a steep, short incline which leads to the sea wall path which is like a dyke path, it's not a formal path. We're just about to have a conversation about how adventurous Liz feels because we are talking a very narrow pathway. My feeling is what we need to do is go up to the top of here so you can take a look and go, 'oh my god, you're having a laugh' or 'actually, yes let's give it a go'.

(Heddon, 2015, 183)

Recasting vulnerability as an environmental ethic contests the story of the subject as self-sufficient and singular. Recognising vulnerability's relationship to interdependency perhaps goes someway to addressing recent critiques of the 'resilience agenda'. As the term resilience gains in currency - 'whatever it is, it appears to be everywhere' (Anderson, 2015, 60), scholars have noted that it is not politically neutral. For MacKinnon and Derickson, for example, 'resilience is inherently conservative insofar as it privileges the restoration of existing systemic relations rather than their transformation' $(2012,262)$. They propose that 'capitalism is itself highly resilient at a systemic level' - the stresses and crises caused by the system and felt within the system are responded to by the system through 'periodic reinvention and restructuring' (261). To promote resilience is to accommodate and normalize the 'uneven effects of neoliberal governance', placing responsibility for dealing with crises onto individuals - or, in an extension of the Conservative-Liberal Democrat Coalition Government's Big Society - onto local communities $(257 ; 263)$. One outcome of 'resilient communities' is reduction in state support. Cretney (2014) offers a more nuanced approach, identifying a number of different trends in resilience discourse, the third of which aims to resist complicity with neoliberalism: 'a countercultural form of activism that mobilises a specific articulation of resilience and transformation' (631).

In the context of Walking Interconnections, we would propose that a countercultural form of activism resides, on the one hand, in the very articulation of resilience and transformation, a performative act of resistance by those normally positioned as vulnerable and a drain on resources; and, on the other, and held in balance with this recognition of resilient skills and practices, an appreciation of vulnerability's contribution to resilience. Our co-researchers' resilience is very much dependent on their vulnerability and their interdependence, that is, on relationality rather than individualised response. From this perspective, resilience recognises the value of vulnerability rather than seeking to overcome it. Whilst interdependency is perhaps 
more apparent because more explicit in the relationships of (some) disabled people (some of the time), as Judith Butler insists, as 'socially constituted bodies' (2004, 20), 'we are fundamentally dependent on others' (xii).

Vulnerability and interdependency are two sides of the same ontological coin, far removed from the idea of the 'masterful', omnipotent subject. Resilience built on the foundations of vulnerability and interdependence promotes not the individualised, independent, neo-liberal subject rightly critiqued by MacKinnon and Derickson, but a relational subject, 'one' who is in community, both impressed upon and impressing upon (Butler, 2004, 27). Borrowing from Butler again, greater recognition of our 'inevitable interdependency' might very well provide the sustaining grounds (180) for a 'global political community' (xii).

Such sustaining grounds are, we argue, essential to sustainability. Geographer Doreen Massey writes evocatively of an immaterial architecture, the architecture of social relations $(2001,462)$, noting that these social relations are practices, and as such are embodied and material. Interdependency is a practice too, equally embodied and material, an openness of one to the other. Acknowledging our vulnerability and an 'ethics of relationship' (Shildrick, 2000, 216) might just allow all of us to practice our interdependency better, a process of resilience necessary to sustaining a diversity of assembled lives, including human ones.

\section{CONCLUSION}

Roz: $\quad$ If we had to choose three words that would describe the walk, what would they be?

Julie: $\quad$ Full of life.

Sharon: Accessible, brilliant, lovely scenery.

Anais: $\quad$ Sunny, relaxing and exploration.

Liz: Revelatory

Roz: Enjoyable.

Liz: $\quad$ Warm

Roz: $\quad$ Thought provoking.

Liz: $\quad$ Opening out, or opening up.

Anais: $\quad$ Hot, continuity, and post-industrial.

Julie: Hot, historical, and water.

Sol: $\quad$ I would say, mindful, because I felt really present, really there enjoying with you in the moment, so I would say present or mindful, energising.

(Heddon, 2015, 187-88)

This chapter has sought to demonstrate the potential contribution of participatory arts based methods to increase participation for a fairer society, influencing environmental discourse, debates on citizenship and inclusive public space, and 
conceptions of resilience. In doing so we have also explored the need to critically review the methods themselves, in this case walking, and how its theory and practice has been largely informed by the assumptions of an ableist culture. The Walking Interconnections project contributed to individual and group agency; framing and presenting the issues in ways (such as the exhibition, audio play and guided walks) that were successful in raising awareness and developing relationships, so impacting on planners and policy makers, as well as the wider community. Extending our dialogic, participatory approach, at our initial sharing of our research in November 2013, we invited attendees - ranging from city councillors to NGO workers - to reflect on the insights which emerged as they encountered our multi-modal research outputs. These were written by attendees onto the reverse side of postcards of Bristol. Comments included: 'An awareness of how barriers (kissing gates etc.) have a premise of keeping things out, without thought of who is going through; the need to incorporate access at an early stage of planning'; 'The enormous potential for cyclists and people with disabilities to work together to address the areas of conflict and for mutual benefit'; 'it's not about physical barriers (or their removal) but about everything: birds, light, relationships, sustainability, etc.'. Walking Interconnections sought to use arts-based methods to enable our co-researchers to perform as experts and, as importantly, to recognise that expertise, to understand themselves as experts. The comments collected at the first dissemination event made tangible to our co-researchers the impact and thus value of their knowledge.

\section{CODA}

Though a collaborative project, Dr. Sue Porter initiated Walking Interconnections. Sue passed away suddenly and unexpectedly in January 2017. A friend and colleague of many, her commitment, expertise, humour and resilience are much missed across diverse communities and landscapes. It was my immense pleasure and privilege to work with Sue on Walking Interconnections and on this co-authored essay. Sue's impact on my research and its direction of travel is immeasurable. I am deeply grateful.

Professor Dee Heddon 


\section{BIBLIOGRAPHY}

Abbott, D. \& Porter, S. (2013) 'Environmental hazard and disabled people: from vulnerable to expert to interconnected', Disability and Society, 28(6): 839-852.

Anderson, B., \& Harrison, P. (2010) 'The Promise of non-representational theories', in Taking-place: non-representational theories and geography', London: Ashgate, pp 1-36.

Anderson, B. (2015) 'What Kind of Thing is Resilience?', Politics, 35(1): 60-66.

Anderson, J. (2005) 'Talking whilst walking: A geographical archaeology of knowledge', Area, 36(3): 254-61.

Andrews, G., Hall, E., Evans, B., Colls, R. (2012) 'Moving beyond walkability: On the potential of health geography', Social Science \& Medicine, 75(11): 1925-32.

Butler, J. (2004) Precarious Life: The Powers of Mourning and Violence, London: Verso.

Carpiano, R.M. (2009) 'Come take a walk with me: The "Go-Along" interview as a novel method of studying the implications of place for health and well-being', Health \& Place, 15(1): 263-72.

Cretney, R. (2014) 'Resilience for Whom? Emerging Critical Geographies of Socioecological Resilience', Geography Compass, 8/9: 627-40.

Crow, L. (2013a) 'Planning and "Walking"', http://walkinginterconnections.com/blog/ $<$ accessed 11 June 2015>

Crow, L. (2013b) 'On Functional and Recreational Walking',

http://walkinginterconnections.com/blog/ <accessed 11 June 2015>

Edensor, T. (2000) 'Walking in the British Countryside: Reflexivity, Embodied Practices and Ways to Escape', Body \& Society, 6(3-4): 81-106.

Fischer, E. M., \& Knutti, R. (2015) 'Anthropogenic contribution to global occurrence of heavy-precipitation and high-temperature extremes', Nature Climate Change, 5: 560-64.

Garland-Thomson, R. (2011) 'Misfits: A Feminist Materialist Disability Concept', Hypatia, 26(3): 591-609.

Garland-Thomson, R. (2012) 'The Case for Conserving Disability', Bioethical Inquiry, 9: 339-55.

Heddon, D. \& Turner, C. (2010), 'Walking women: interviews with artists on the move', Performance Research, 15(4): 14-22. 
Heddon, D. \& Turner, C. (2012) 'Walking women: shifting the tales and scales of mobility', Contemporary Theatre Review, 22(2): 224-36.

Heddon, D. (2012) 'Turning 40: 40 turns. Walking \& friendship', Performance Research, 17(2): 67-75.

Heddon, D. \& Myers, M. (2014) 'Stories from the walking library', Cultural Geographies, 21(4): 639-55.

Heddon, D. (2015) 'Going for a walk: a verbatim play', Studies in Theatre and Performance 35(3): 177-88.

Imrie, R. \& Thomas, H. (2008) 'The interrelationships between environment and disability', Local Environment, 13(6): 477-83.

Ingold, T. \& Vergunst J.L. (2008) Ways of Walking: Ethnography and practice on foot, London: Ashgate.

Ingold, T. (2010) 'Footprints through the weather-world: walking, breathing, knowing', Journal of the Royal Anthropological Institute, 121-139.

Kafer, A. (2013) Feminist, Queer, Crip. Bloomington: Indiana UP.

John, B. \& Kagan, S. (2014), 'Extreme Climate Events as Opportunities for Radical Open Citizenship', Open Citizenship, 5(1): 60-75.

Leipoldt, E.A. (2006) 'Disability experience: a contribution from the margins towards a sustainable future', Journal of Futures Studies, 10(3): 15-32.

Lister, R. (2003), Citizenship: Feminist Perspectives, London: Palgrave Macmillan.

Mackinnon, D. \& Derickson, K. D. (2012) 'From resilience to resourcefulness: A critique of resilience policy and activism', Progress in Human Geography, 37(2): 253 -70 .

Meekosha, H. \& Shuttleworth, R. (2009) 'What's So "Critical” About Critical Disability Studies?', Australian Journal of Human Rights, 15(1): 47-75.

Massey, D. (2001) 'Living in Wythenshawe', in I. Borden, J. Kerr, J. Rendell and A. Pivaro (eds) The Unknown City: Contesting Architecture and Social Space, Cambridge, MA: MIT Press, pp 458-75.

Morton, T. (2010) The Ecological Thought, Harvard University Press.

Pink, S, et al. (2010) 'Walking across disciplines: from ethnography to arts practice', Visual Studies, 25(1): 1-7.

Ray, S. J. (2009) 'Risking Bodies in the Wild: The "Corporeal Unconscious" of American Adventure Culture', Journal of Sport and Social Issues, 33(3): 257-84. 
Rendell, J. (2008) Art and Architecture: A Place Between, London: Routledge Shildrick, M. (2000) 'Contagious Encounters and the Ethics of Risk', Journal of Medical Humanities, 21(4): 215-27.

Wiseman, P. (2014) Everyday Embodied Citizenship and Disabled Young People, http://www.glasgowsociology.com/everyday-embodied-citizenship-and-disabledyoung-people/ <accessed 13 June 2015>

Wunderlich, F. M. (2005), 'Walking and Rhythmicity: sensing urban space', Walk21VI Conference, Zurich http://citeseerx.ist.psu.edu/viewdoc/download?doi=10.1.1.580.8526\&rep=rep1\&type =pdf <accessed 20 May 2017> 